\title{
Performance Monitoring Techniques Supporting Cognitive Optical Networking
}

\author{
Caballero Jambrina, Antonio; Borkowski, Robert; Zibar, Darko; Tafur Monroy, Idelfonso
}

Published in:

Proceedings of ICTON 2013

Link to article, DOI:

10.1109/ICTON.2013.6602786

Publication date:

2013

Link back to DTU Orbit

Citation (APA):

Caballero Jambrina, A., Borkowski, R., Zibar, D., \& Tafur Monroy, I. (2013). Performance Monitoring Techniques Supporting Cognitive Optical Networking. In Proceedings of ICTON 2013 IEEE.

https://doi.org/10.1109//CTON.2013.6602786

\section{General rights}

Copyright and moral rights for the publications made accessible in the public portal are retained by the authors and/or other copyright owners and it is a condition of accessing publications that users recognise and abide by the legal requirements associated with these rights.

- Users may download and print one copy of any publication from the public portal for the purpose of private study or research.

- You may not further distribute the material or use it for any profit-making activity or commercial gain

- You may freely distribute the URL identifying the publication in the public portal

If you believe that this document breaches copyright please contact us providing details, and we will remove access to the work immediately and investigate your claim. 


\title{
Performance Monitoring Techniques Supporting Cognitive Optical Networking
}

\author{
Antonio Caballero, Robert Borkowski, Darko Zibar and Idelfonso Tafur Monroy \\ DTU Fotonik - Department of Photonics Engineering, Technical University of Denmark, \\ Oersteds Plads 343, 2800 Lyngby, Denmark \\ Tel: (+45) 4525 5173, Fax (+45) 4593 6581, e-mail: acaj@fotonik.dtu.dk
}

\begin{abstract}
High degree of heterogeneity of future optical networks, such as services with different quality-of-transmission requirements, modulation formats and switching techniques, will pose a challenge for the control and optimization of different parameters. Incorporation of cognitive techniques can help to solve this issue by realizing a network that can observe, act, learn and optimize its performance, taking into account end-to-end goals.

In this letter we present the approach of cognition applied to heterogeneous optical networks developed in the framework of the EU project CHRON: Cognitive Heterogeneous Reconfigurable Optical Network. We focus on the approaches developed in the project for optical performance monitoring, which enable the feedback from the physical layer to the cognitive decision system by providing accurate description of the performance of the established lightpaths.
\end{abstract}

Keywords: optical networks, cognition, dynamic optical networks, optical performance monitoring.

\section{INTRODUCTION}

Optical networks are nowadays becoming more heterogeneous, ranging from different types of services, switching paradigms to physical interfaces. Therefore, network operators are facing the challenge of supporting a plethora of services, each with individual requirements on quality of service (QoS). Operators have also available different transmission technologies for their optical transport networks, such as coding, modulation formats or data rates. Moreover, in the short and medium term, optical networks may simultaneously support different switching paradigms such as semi-static and dynamic circuit switching. Hence, a key issue of highly heterogeneous networks is how to efficiently control and manage network resources while fulfilling user demands and complying with QoS requirements.

A solution for such a scenario may come from cognitive networks. A cognitive network is defined as "a network with a process that can perceive current network conditions, and then plan, decide and act on those conditions. The network can learn from these adaptations and use them to make future decisions, all while taking into account end-to-end goals" [1]. Hence, a cognitive network should provide better end-to-end performance than a non-cognitive network. Cognitive paradigm have already shown to be a promising solution for wireless networks [1,2]. Cognition is also applicable to optical communication architectures [3-5], since it can offer flexibility to telecom operators by optimizing simultaneously physical layer components' characteristics (modulation format, forward error correction - FEC, wavelength capacity, etc.) and network layer parameters (bandwidth, number of simultaneous lightpaths, QoS, etc.) depending on application or service requirements.

The aim of CHRON is to develop a showcase network architecture and a control plane that efficiently uses resources in a heterogeneous scenario, while fulfilling the QoS requirements of each type of services. To achieve this goal, CHRON relies on cognition, so that control decisions must be made with an appropriate knowledge of current status, and supported by a learning process to improve the performance with the acquired past knowledge. In this paper, we present in section 1.1 the global CHRON architecture. In section 2 we describe the approaches followed in CHRON for optical performance monitoring (OPM). In section 3 we describe a Qualityof-Transmission (QoT) estimator that combines OPM with cognition. We finish with conclusions and future work in section 4.

\subsection{CHRON Architecture}

The central element of our proposed CHRON architecture is a cognitive decision system (CDS).CDS runs a generic cognitive decision process which is in charge of taking decisions, which are in turn based on the observed network behavior. Figure 1 presents the building blocks of the CDS module, as well as their relationship to the network monitoring system and the control and management system. This architecture shows how the CDS implements the cognitive loop [1]. The network monitoring system gathers the network status and store it into a generic knowledge database. Separately, there are several specific knowledge databases, containing all the information associated with each of the cognitive processes. Therefore, there are as many specific knowledge databases as cognitive processes in the CDS. These databases are updated through a specific learning module, which is associated to a single cognitive process per database. Consequently, the cognitive process module can access the general and specific databases to retrieve and update them. Finally, the specific cognitive process provides the decision and action information to the control plane when request arrives. Based on this 
architecture, a robust optical signal monitoring needs to be developed in order to feed the CDS with information and implement intelligence into the network.

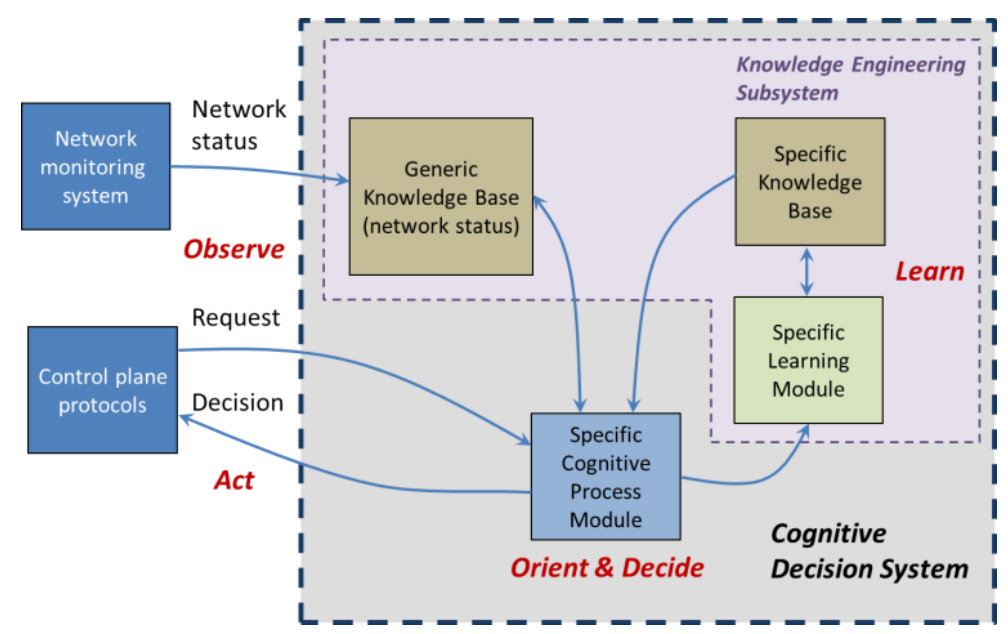

Figure 1. Building blocks of the cognitive decision system as defined in the CHRON project

\section{OPTICAL PERFORMANCE MONITORING}

OPM is a basic mechanism providing inputs to the cognitive processes. In traditional scenarios, OPM is performed by monitoring the signal tapped before the receiver with devices such as an oscilloscope or an optical spectrum analyzer [6]. Combining the advantage of coherent detection, where both amplitude and phase are recovered with digital sampling and signal processing, forms an inexpensive and robust alternative to traditional OPM methods. Figure 2a) shows location of an OPM subsystem in the digital signal processing (DSP) module of a coherent receiver. The received optical field is transferred into electrical domain for further treatment with DSP algorithms. In the sense used here, monitoring can be understood twofold: 1) observation of the received signal performance parameters that indicate detrimental effects of signal generation, fiber-optic transmission and reception (OPM); and 2) observation of the received signal to enable advanced receiver functionalities, such as reconfiguration of the software-defined digital coherent receiver.

Typical performance indicators used in the digital communication systems include quality factor $Q^{2}$, error vector magnitude (EVM), modulation error ratio (MER), or pre- and ultimately post-FEC bit error rate (BER). Those are, however, synthetic indicators where information about the contribution of each specific impairment affecting the signal is lost. Since in a digital coherent receiver it is possible to compensate deterministic linear impairments, it is highly desirable to separate the influence of all impairments acting upon the signal in order to efficiently mitigate them in DSP. Most of impairments that affect the signal performance in the coherent fiberoptic transmission system are listed in Table 1, which includes effects originating in the transmitter, fiber-optic link and the receiver [7]. OPM techniques can be divided into data-aided (DA) and non-data-aided (NDA). Comparison between both approaches is shown in Table 2.

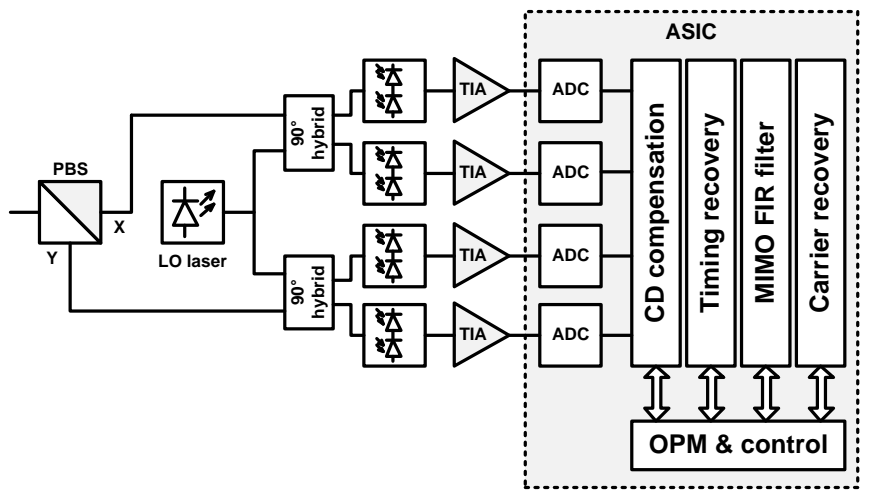

a)

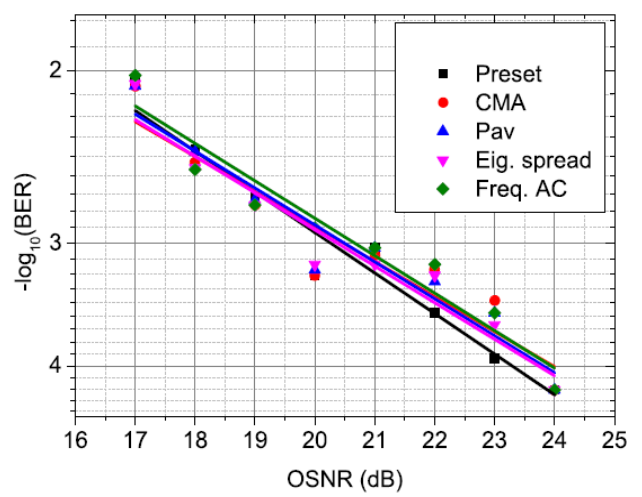

b)

Figure 2. a) Typical structure of a digital coherent receiver with CD monitoring and equalization block. $b$ ) Performance of different CD compensation methods [8]. Methods: Preset-reference; CMA - constant modulus algorithm; Pav-mean signal power; Eig. spread-eigenvalue spread; Freq. AC-frequency spectrum autocorrelation. 
Table 1. Important impairments in a fiber-optic coherent transmission system

\begin{tabular}{|l|l|}
\hline \multicolumn{1}{|c|}{ Transmitter } & \multicolumn{1}{c|}{ Link } \\
\cline { 1 - 2 } In-phase/quadrature (I/Q) imbalance & Amplifier spontaneous emission (ASE) \\
Electrical distortion in the generation stage & Chromatic dispersion (CD) \\
& Differential group delay (DGD) \\
\hline \multicolumn{1}{|c|}{ Receiver } & Polarization mode dispersion (PMD) \\
\cline { 1 - 1 } Timing misalignment & Polarization dependent loss (PDL) \\
Local oscillator offset & Nonlinear effects due to high input power \\
Polarization mixing angle & Linear and nonlinear effects due to copropagation \\
\hline
\end{tabular}

Table 2. Summary of advantages and disadvantages of NDA and DA techniques for digital OPM [7].

\begin{tabular}{|c|l|l|}
\cline { 2 - 3 } \multicolumn{1}{c|}{} & \multicolumn{1}{c|}{ Data-aided } & \multicolumn{1}{c|}{ Non-data-aided } \\
\hline \multirow{2}{*}{ Pros } & $\begin{array}{l}\text { High accuracy } \\
\text { Guaranteed convergence } \\
\text { Short convergence length }\end{array}$ & $\begin{array}{l}\text { No training overhead } \\
\text { Compatible with legacy nodes } \\
\text { Efficient for short memory channels }\end{array}$ \\
\hline & $\begin{array}{l}\text { Training overhead } \\
\text { Incompatible with legacy nodes }\end{array}$ & $\begin{array}{l}\text { Long convergence time } \\
\text { Inferior accuracy }\end{array}$ \\
\hline
\end{tabular}

In DA approach, a training sequence (TS) is transmitted along the message. Based on the received TS and knowing the ideal transmitted TS, the receiver can estimate the transfer function of the system (zero-forcing solution). This allows for accurate channel monitoring $[9,10]$. The NDA approach on the other hand does not use any predefined sequences and relies on statistics of random transmitted data. An example of blind estimation performance is shown in Fig. 2b) for CD estimation of polarization division multiplexed (PDM) quadrature phase shift keying (QPSK) system after $80 \mathrm{~km}$ of fiber transmission using four different estimation methods [8].

Another important contribution in the monitoring subsystem is the modulation format recognition (MFR) which enables software-defined algorithms of the receiver. Since for every modulation format the algorithms that shall be applied for optimal signal demodulation differ slightly, the MFR block shall continually observe the signal to determine the modulation format used, and use the most optimal DSP algorithms. At the same time MFR allows for operation of dynamically switched networks in which the arriving signal may be of unknown nature and the receiver has to determine the way to demodulate it. We have developed a technique for modulation format recognition that is insensitive to frequency offset and polarization mixing based on Stokes space receiver and Bayesian expectation maximization and Gaussian mixture models [11]. Figure 3 shows the experimental results for PDM-QPSK and PDM-16-quadrature and amplitude modulation (PDM-16QAM) demodulated and the corresponding clustering identification using the Stokes space MFR.
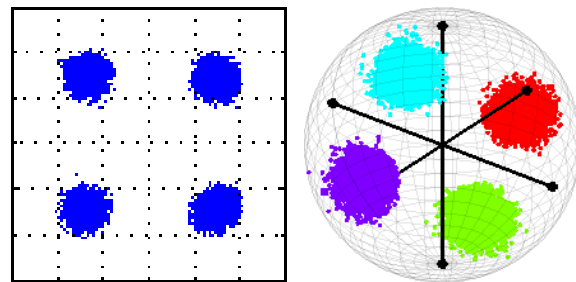

a)
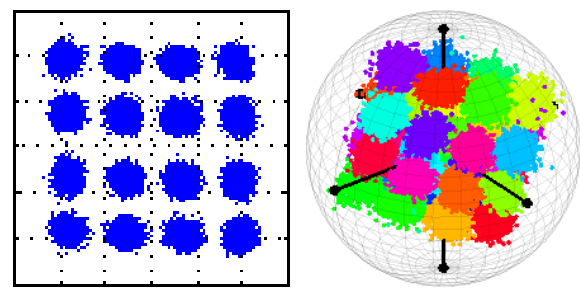

b)



c)

Figure 3. Modulation format recognition in Stokes space, experimental results for a) DP-QPSK b) DP-16QAM c) Experimental demonstration of QoT based on CBR for PD-QPSK WDM networks with high successful ratio for small $K B$ [13]. 


\section{QUALITY-OF-TRANSMISSION ESTIMATOR}

The aim of the QoT estimator is to make a prediction of signal quality of the new lightpaths to be established in the network and to address its impact on existing connections. The approach of CHRON combines the information of past history and the feedback from the network monitoring system. This information may be used to update its knowledge base and thus adapt to changing conditions, like component ageing or substitution.

The cognitive operation of this module relies on the utilization of a data mining technique called case-based reasoning (CBR). The CBR approach achieves more than $99 \%$ successful classifications of optical connections, and is much faster for on-line operation than an existing non-cognitive approach, thus demonstrating the advantages of cognition. In [12] the basic cognitive QoT estimator was enhanced by including learning and forgetting capabilities. These capabilities are used to optimize the set of experiences stored in the knowledge base, and thus to improve performance accelerating the classification procedure by an order of magnitude. The CBR QoT estimator was experimentally validated in [13]. We implemented a wavelength division multiplexed, homogeneous point-to-point optical transmission system consisting of 5 channels carrying $80 \mathrm{~Gb} / \mathrm{s}$ PDM-QPSK, with a number of adjustable parameters such as: optical launch power, fiber link length, and number of copropagating channels, in order to support different lightpath and system configurations. The estimator performance is shown in Fig. 4, where a total of 150 different link configurations were measured and channel error-vector magnitude (EVM) calculated. The estimator was able to show high successful classification ratio, over $75 \%$ even for small KB of only 150 cases.

\section{CONCLUSION AND FUTURE WORK}

Cognitive heterogeneous reconfigurable optical networks are expected as a breakthrough technology to implement future optical communication networks in highly heterogeneous environment. In this paper we have described the approach followed in the CHRON project to include cognitive techniques in order to efficiently control and manage an optical network. In this context, there are several research lines that CHRON is working on. In optical performance monitoring, the development of robust algorithms for signal monitoring is being investigated to provide accurate and fast information to the cognitive decision system on the status of the physical layer.

\section{ACKNOWLEDGMENT}

The research leading to these results was partly supported by the CHRON project (Cognitive Heterogeneous Reconfigurable Optical Network) with funding from the European Community's Seventh Framework Program [FP7/2007-2013] under grant agreement $\mathrm{n}^{\circ} 258644$.

\section{REFERENCES}

[1] R. W. Thomas, et al.: Cognitive networks: adaptation and learning to achieve end-to-end performance objectives, IEEE Commun. Mag., vol. 44 no. 12, pp. 51-57, 2006.

[2] N. Devroye et al.: Cognitive radio networks, IEEE Signal Process. Mag., vol. 25 no. 6, pp. 12-23 (2008).

[3] R. J. Durán, et al.: Cognition to Design Energetically Efficient and Impairment Aware Virtual Topologies for Optical Networks, in Proc. ONDM, 1-6, 2012.

[4] G. S. Zervas and D. Simeonidou: Cognitive optical networks: Need, requirements and architecture, in Proc. ICTON 2010, paper We.C1.3.

[5] W. Wei, et al:: Cognitive optical networks: key drivers, enabling techniques, and adaptive bandwidth services, IEEE Comm. Mag., vol. 50, pp. 106-113, 2012.

[6] C. K. Chan: Optical performance monitoring: advanced techniques for next-generation photonic networks, ed. Elsevier, 2010.

[7] M. Kuschnerov, et al.: DSP for Coherent Single-Carrier Receivers, IEEE/OSA J. Lightw. Technol., vol. 27, pp. 3614-3622, 2009.

[8] R. Borkowski, et al.: Experimental demonstration of adaptive digital monitoring and compensation of chromatic dispersion for coherent DP-QPSK receiver, Opt. Express vol. 19, pp. B728-B735, 2011.

[9] F. Pittala, et al.: Data-aided Frequency-Domain channel estimation for CD and DGD monitoring in coherent transmission systems, in Proc. Photonics Conference (PHO) 2011, pp. 897-898, Oct. 2011.

[10] F. Pittala, et al.: Joint PDL and in-band OSNR monitoring supported by data-aided channel estimation, OFC/NFOEC 2012, March 2012, paper OW4G.2.

[11] R. Borkowski, et al.: Optical Modulation Format Recognition in Stokes Space for Digital Coherent Receivers, OFC/NFOEC 2013, March 2013, paper OTh3B.3.

[12] T. Jiménez, et al.: A Cognitive Quality of Transmission Estimator for Core Optical Networks, IEEE/OSA J. Lightw. Technol., vol. 31, pp. 942-951, 2013.

[13] A. Caballero, et al.: Experimental demonstration of a cognitive quality of transmission estimator for optical communication systems, Opt. Express, vol. 20, pp. B64-B70, 2012. 